\title{
Evaluation of the appropriate use of commonly prescribed fluoroquinolones and the risk of dysglycemia
}

\author{
Wissam K Kabbara' \\ Wijdan H Ramadan' \\ Peggy Rahbany ${ }^{2}$ \\ Souhaila Al-Natour ${ }^{3}$ \\ 'Department of Pharmacy Practice, \\ School of Pharmacy, Lebanese \\ American University, Byblos, Lebanon; \\ ${ }^{2}$ Children's National Medical Center, \\ Washington, DC, USA; ${ }^{3}$ Medex \\ Pharmaceutical Company, Beirut, \\ Lebanon
}

This article was published in the following Dove Press journal:

Therapeutics and Clinical Risk Management

22 April 2015

Number of times this article has been viewed

Background: Fluoroquinolones are among the most widely prescribed antibiotics. However, concerns about increasing resistant microorganisms and the risk of dysglycemia associated with the use of these agents have emerged.

Objective: The primary objective of the study was to evaluate the appropriate use of commonly prescribed fluoroquinolones, including appropriate indication, dose, dose adjustment in renal impairment, and duration of treatment. The secondary objective was to investigate the dysglycemic effect of fluoroquinolone use (hypoglycemia and/or hyperglycemia) in diabetic and nondiabetic patients.

Methods: A prospective observational study at a teaching hospital in Lebanon was conducted over a 6-month period. A total of 118 patients receiving broad-spectrum fluoroquinolones (levofloxacin, ciprofloxacin, and moxifloxacin) were identified. Patients were mainly recruited from internal medicine floors and intensive care units.

Results: The final percentage for the appropriate indication, dose, and duration of fluoroquinolone therapy was $93.2 \%, 74.6 \%$, and $57.6 \%$, respectively. A total of $57.1 \%$ of the patients did not receive the appropriate dose adjustment according to their level of renal impairment. In addition, dysglycemia occurred in both diabetic and nondiabetic patients. Dysglycemia was more frequently encountered with ciprofloxacin (50.0\%), followed by levofloxacin (42.4\%) and moxifloxacin (7.6\%). Hyperglycemia was more common than hypoglycemia in all groups. The highest incidence of hyperglycemia occurred with levofloxacin (70.0\%), followed by ciprofloxacin (39.0\%) and moxifloxacin (33.3\%). In contrast, hypoglycemia did not occur in the ciprofloxacin group, but it was more common with moxifloxacin (11.1\%) and levofloxacin (6.0\%).

Conclusion: The major clinical interventions for the future will adjust the dose and duration of therapy with commonly prescribed fluoroquinolones. The incidence of hypoglycemia was less common than hyperglycemia.

Keywords: fluoroquinolones, ciprofloxacin, levofloxacin, moxifloxacin, dysglycemia

\section{Introduction}

Fluoroquinolones are one of the most commonly prescribed classes of antibiotics worldwide. ${ }^{1}$ The development of newer generations of fluoroquinolones has expanded the traditional Gram-negative coverage to Gram-positive and anaerobic organisms. ${ }^{2}$ Fluoroquinolones are mainly used in the treatment of pneumonia and urinary tract infections. ${ }^{3}$

The increased use of fluoroquinolones has led to the emergence of recent concerns about resistance. The major factor is the inappropriate use of these agents in both community and hospital settings. ${ }^{4}$ In the Lebanese population, resistance to ciprofloxacin was estimated to be 40\%-50\% for Escherichia coli and Klebsiella spp. in 2013. ${ }^{5}$ Inappropriate use of fluoroquinolones is linked to indication, dose, and duration of therapy.
Correspondence: Wijdan H Ramadan Department of Pharmacy Practice, School of Pharmacy, Lebanese American University, PO Box 36 - F 53 Byblos, Lebanon

Tel +9619547249 ext 2267

Fax +9619547256 ext 2897

Email wramadan@lau.edu.lb 
Additionally, concerns about the safety of fluoroquinolone antimicrobials have been addressed. ${ }^{6,7}$ Serious adverse events have led to the withdrawal of temafloxacin (because of hemolysis, renal failure, and hypoglycemia), ${ }^{8,9}$ grepafloxacin and sparfloxacin (because and QT prolongation), ${ }^{9,10}$ and trovafloxacin (because of hepatotoxicity). ${ }^{10,11}$ Furthermore, postmarketing surveillance of adverse events includes dysglycemia (hypoglycemia or hyperglycemia). On April 27, 2006, Bristol-Myers Squibb (New York, NY, USA) announced that it would stop manufacturing Tequin ${ }^{\circledR}$ (gatifloxacin), as the drug has been associated with potentially fatal blood glucose fluctuations. ${ }^{12}$

Both hypoglycemic and hyperglycemic episodes occur during therapy. ${ }^{13}$ Recent data show that fluoroquinolones can cause dysglycemia as an adverse effect in diabetic and nondiabetic patients. ${ }^{14}$ Although the exact mechanism of glucose homeostasis alteration is not fully known, animal studies suggest that fluoroquinolones can enhance insulin secretion by blocking adenosine triphosphate-sensitive $\mathrm{K}+$ channels in pancreatic B-cells, ${ }^{15-18}$ leading to hypoglycemia. The hypoglycemic episodes have been mainly observed in patients receiving concomitant sulfonylurea antidiabetic agents. ${ }^{19}$ On the other hand, the mechanism of hyperglycemia is unclear. It may be due to a direct drug effect on glucose metabolism, or it may be a result of multiple confounding factors. ${ }^{20}$ In addition, some recent findings imply that disturbed cellular glucose transport and GLUT1 function may underlie the dysglycemic effects of ciprofloxacin and levofloxacin. ${ }^{21}$ This adverse effect has important clinical implications, especially for diabetic patients. ${ }^{22}$

\section{Aim of the study}

The primary objective of the study was to evaluate the appropriate use of commonly prescribed fluoroquinolones, including appropriate indication, dose, dose adjustment in renal impairment, and duration of treatment. The secondary objective was to investigate the dysglycemic effect of fluoroquinolone use in diabetic and nondiabetic patients.

\section{Ethical approval}

The study was approved by the Hospital Institutional Review Board and informed consent was not required since there were no deviations from optimal medical practice.

\section{Methods}

\section{Setting and design}

A prospective study at a teaching hospital in Lebanon was conducted over a 6-month period. One hundred and eighteen patients receiving broad-spectrum fluoroquinolones (levofloxacin, ciprofloxacin, and moxifloxacin) were identified. Patients were mainly recruited from internal medicine floors and intensive care units. Patients were analyzed according to drug, indication, dose, and duration of therapy.

\section{Sources of data}

Electronic charts using the hospital database were identified, which included each patient's chief complaint, past medical history, history of present illness, and all medications with their doses, routes of administration, and durations of therapy. Patients were followed up from initiation of fluoroquinolone use to the discharge date. A data collection form was used to evaluate the appropriate use of fluoroquinolones, which included patient demographic information, past medical history, the use of antidiabetic drugs, and pertinent laboratory tests (fasting blood glucose, hemoglucose test, and glycated hemoglobin $\left[\mathrm{HbA}_{1 \mathrm{C}}\right]$, when available). The assessment was based on relevant guidelines from the Infectious Disease Society of America, ${ }^{23-28}$ manufacturer package inserts, ${ }^{29-31}$ and clinical judgment. In addition, the relative risk of dysglycemia associated with fluoroquinolones among the 118 hospitalized patients, as well as the impact of this important clinical outcome, will be reported.

\section{Results}

\section{Appropriateness of treatment}

During the 6-month period, 118 hospitalized patients received fluoroquinolones (levofloxacin, ciprofloxacin, and moxifloxacin) for the treatment of their infections (Table 1).

The characteristics of patients recruited in the study are shown in Table 2. Male sex was dominant (62.7\%) with a mean age of 64 years versus 61 years for females. A total of $14.0 \%$ of the population were diabetic and $29.7 \%$ had renal impairment. Concomitant drug intake was evaluated, and baseline blood glucose was monitored in only $21.2 \%$ patients (Table 2). Around one-third of the patients (32.2\%)

Table I Summary of fluoroquinolone indications encountered in the study

Community-acquired pneumonia
Hospital-acquired pneumonia/ventilator-associated pneumonia
Chronic obstructive pulmonary disease exacerbation
Diabetic foot infection
Skin and soft tissue infection
Intra-abdominal infection
Urinary tract infection
Prophylaxis for transurethral resection of bladder tumor
Prophylaxis for endoscopic retrograde cholangiopancreatography

Community-acquired pneumonia

Hospital-acquired pneumonia/ventilator-associated pneumonia

Diabetic foot infection

Skin and soft tissue infection

Prophylaxis for endoscopic retrograde cholangiopancreatography 
Table 2 Baseline characteristics of the study population $(\mathrm{N}=\mid$ I8)

\begin{tabular}{ll}
\hline Characteristics & Percentage \\
\hline Demographic and medical characteristics & \\
Female sex & $37.3 \%$ \\
Male sex & $62.7 \%$ \\
Mean female age & 61 years \\
Mean male age & 64 years \\
Renal impairment & $29.7 \%$ \\
Diabetic & $14.0 \%$ \\
Nondiabetic & $86.0 \%$ \\
Drug therapy & \\
Steroids & $32.2 \%$ \\
Insulin therapy & $11.0 \%$ \\
Oral antidiabetic agents & $5.1 \%$ \\
Combination & \\
Steroids + oral antidiabetic & $4.2 \%$ \\
Steroids + insulin & $2.5 \%$ \\
Steroids + insulin + oral antidiabetic & $0.8 \%$ \\
Baseline blood glucose level* & \\
Normal & $51.8 \%$ \\
Hyperglycemia & $47.1 \%$ \\
Hypoglycemia & $1.1 \%$ \\
\hline
\end{tabular}

Note: *Baseline blood glucose level was monitored in only $21.2 \%$ of the patients. Abbreviation: $\mathrm{N}$, total number.

were on concomitant steroid therapy for various indications and different durations of therapy.

Prior to starting antibiotic therapy, cultures were taken from different sites of infection: blood; urine; sputum; pus; bone; cerebrospinal fluid; and deep tracheal aspirate in 70 patients $(59.3 \%)$. Cultures were positive for bacterial microorganism(s) in $62.9 \%$ of the collected specimens. Gram-negative bacteria were the most commonly isolated microorganisms (Table 3).

Table 3 Microorganisms isolated in positive cultures during the study

\begin{tabular}{l}
\hline Gram-positive \\
Staphylococcus spp. \\
Streptococcus spp. \\
Enterococcus spp. \\
Gram-negative \\
Pseudomonas spp. \\
Serratia spp. \\
Escherichia coli \\
Klebsiella spp. \\
Extended spectrum beta-lactamase (E. coli, Klebsiella spp.) \\
Proteus spp. \\
Acinetobacter spp. \\
Citrobacter spp. \\
Morganella spp. \\
Alcaligenes xylosoxidans \\
Anaerobes \\
Candida spp.
\end{tabular}

\section{Indication}

\section{Ciprofloxacin}

A total of 59 patients received ciprofloxacin. The most common indication for ciprofloxacin was diabetic foot infection (12 patients), followed by prophylaxis for transurethral resection of bladder tumor (eleven patients), urinary tract infections (ten patients), skin and soft tissue infections (six patients), prophylaxis for endoscopic retrograde cholangiopancreatography (five patients), intra-abdominal infections (three patients), community-acquired pneumonia (one patient), nosocomial pneumonia (one patient), and other types of infections (ten patients). The final results showed that $96.6 \%$ of the patients received ciprofloxacin for an appropriate indication (Table 4).

\section{Levofloxacin}

A total of 50 patients received levofloxacin. Most patients were treated with levofloxacin for community-acquired pneumonia (43 patients), followed by chronic obstructive pulmonary disease exacerbations (five patients), intra-abdominal infections (one patient), and other types of infections (one patient). We observed that $94.0 \%$ of levofloxacin indications were appropriate (Table 4).

\section{Moxifloxacin}

Only nine patients received moxifloxacin. The two major indications for moxifloxacin were community-acquired pneumonia (three patients) and chronic obstructive pulmonary disease exacerbations (two patients). In addition, one patient received moxifloxacin for the treatment of nosocomial pneumonia, one patient for the treatment of a urinary tract infection, and two patients for other types of infections. In the study, moxifloxacin was used for an appropriate indication in $66.7 \%$ of the patients (Table 4 ).

\section{Dose}

In the levofloxacin and ciprofloxacin groups, 32 patients (64.0\%) and 47 patients (79.7\%) received the appropriate dose, respectively. All patients in the moxifloxacin group received

Table 4 Summary of the results of fluoroquinolone indications

\begin{tabular}{lll}
\hline Fluoroquinolone & Indication \\
\cline { 2 - 3 } & Appropriate & Inappropriate \\
\hline Ciprofloxacin & $96.6 \%$ & $3.4 \%$ \\
Levofloxacin & $94.0 \%$ & $6.0 \%$ \\
Moxifloxacin & $66.7 \%$ & $33.3 \%$ \\
Weighted average percentage & $93.2 \%$ & $6.8 \%$ \\
\hline
\end{tabular}

Note: The final weighted average percentage of the appropriate indication for fluoroquinolones is $93.2 \%$. 
Table 5 Fluoroquinolone doses in different indications

\begin{tabular}{lll}
\hline Fluoroquinolone & Dose & \\
\cline { 2 - 3 } & Appropriate (n) & Inappropriate (n) \\
\hline Ciprofloxacin & & 0 \\
CAP & 1 & 0 \\
HAP/VAP & 1 & 2 \\
Diabetic foot infection & 10 & 1 \\
SSTI & 5 & 1 \\
Prophylaxis for TURBT & 10 & 0 \\
Prophylaxis for ERCP & 5 & 0 \\
IAI & 3 & 8 \\
UTI & 2 & 0 \\
Others & 10 & \\
Levofloxacin & & 15 \\
CAP & 28 & 1 \\
COPD exacerbation & 4 & 1 \\
IAI & 0 & 1 \\
Others & 0 & \\
Moxifloxacin & & 0 \\
CAP & 3 & 0 \\
HAP/VAP & 1 & 0 \\
COPD exacerbation & 2 & 0 \\
UTI & 1 & 0 \\
Others & 2 & \\
\hline Abreviatons & & \\
\hline
\end{tabular}

Abbreviations: $n$, number of patients; CAP, community-acquired pneumonia; COPD, chronic obstructive pulmonary disease; HAP, hospital-acquired pneumonia; VAP, ventilator-associated pneumonia; SSTI, skin and soft tissue infection; TURBT, transurethral resection of bladder tumor; ERCP, endoscopic retrograde cholangiopancreatography; UTI, urinary tract infection; IAI, intra-abdominal infection.

the correct dose (Tables 5 and 6). The appropriate doses per indication are mentioned in the Supplementary materials.

\section{Dose adjustment in renal impairment}

In the study, renal impairment that required a dosage adjustment for levofloxacin and ciprofloxacin was defined as a creatinine clearance $\leq 50 \mathrm{~mL} /$ minute. Moxifloxacin does not require dosage adjustment in kidney dysfunction. Out of 118 patients, 35 patients had renal impairment. A total of 12 and eight patients in the levofloxacin and ciprofloxacin groups, respectively, did not receive the correct dosage adjustment according to their level of renal impairment. Two patients on hemodialysis and one patient with a creatinine

Table 6 Summary of the doses of fluoroquinolone therapy

\begin{tabular}{lll}
\hline Fluoroquinolone & Dose \\
\cline { 2 - 3 } & Appropriate & Inappropriate \\
\hline Ciprofloxacin & $79.7 \%$ & $20.3 \%$ \\
Levofloxacin & $64.0 \%$ & $36.0 \%$ \\
Moxifloxacin & $100.0 \%$ & $0.0 \%$ \\
Weighted average percentage & $74.6 \%$ & $25.4 \%$ \\
\hline
\end{tabular}

Note: The final weighted average percentage of the appropriate dose of fluoroquinolones is $74.6 \%$.
Table 7 Summary of patients with renal impairment

\begin{tabular}{lll}
\hline Fluoroquinolone & $\begin{array}{l}\text { Number of patients } \\
\text { with renal impairment }\end{array}$ & $\begin{array}{l}\text { Inappropriate dose } \\
\text { adjustment (\%) }\end{array}$ \\
\hline Ciprofloxacin & 18 & 44.4 \\
Levofloxacin & 14 & 85.7 \\
Moxifloxacin & 3 & $\begin{array}{l}\text { No need for dose } \\
\text { adjustment }\end{array}$ \\
\hline
\end{tabular}

clearance of $32.7 \mathrm{~mL} /$ minute were treated with moxifloxacin (Table 7).

\section{Duration}

In the levofloxacin, ciprofloxacin, and moxifloxacin groups, 30 patients $(60.0 \%), 31$ patients $(52.5 \%)$, and seven patients $(77.8 \%)$ received the appropriate duration of therapy, respectively (Table 8).

\section{Dysglycemia}

In the study, we defined hyperglycemia when glucose levels were $>150 \mathrm{mg} / \mathrm{dL}$ and hypoglycemia when they were $<70 \mathrm{mg} / \mathrm{dL}$. To evaluate the relative risk of dysglycemia associated with fluoroquinolone use, we grouped patients into one of two groups: diabetics and nondiabetics. The majority of the population in the study were nondiabetic; the incidence of dysglycemia with ciprofloxacin, levofloxacin, and moxifloxacin in diabetic and nondiabetic patients is reported in Table 9. Dysglycemia occurred more frequently with ciprofloxacin $(50.0 \%)$, followed by levofloxacin (42.4\%) and moxifloxacin (7.6\%) (Table 9).

\section{Blood glucose monitoring}

Blood glucose was monitored using pertinent laboratory tests such as fasting blood glucose, hemoglucose test, and $\mathrm{HbA}_{1 \mathrm{C}}$ in $49.2 \%, 90.0 \%$, and $77.8 \%$ of patients in the ciprofloxacin, levofloxacin, and moxifloxacin groups, respectively (Table 10). Baseline blood glucose was monitored in $21.2 \%$ of the patients and they were classified according to normal blood glucose levels, hypoglycemia, or hyperglycemia (Table 10).

Table 8 Summary of the duration of fluoroquinolone therapy

\begin{tabular}{lll}
\hline Fluoroquinolone & Duration \\
\cline { 2 - 3 } & Appropriate & Inappropriate \\
\hline Ciprofloxacin & $52.5 \%$ & $47.5 \%$ \\
Levofloxacin & $60.0 \%$ & $40.0 \%$ \\
Moxifloxacin & $77.8 \%$ & $22.2 \%$ \\
Weighted average percentage & $57.6 \%$ & $42.4 \%$ \\
\hline
\end{tabular}

Note: The final weighted average percentage of the appropriate duration of fluoroquinolone therapy is $57.6 \%$. 
Table 9 Incidence of dysglycemia in diabetic and nondiabetic patients

\begin{tabular}{llll}
\hline Fluoroquinolone & $\begin{array}{l}\text { Patients developing } \\
\text { dysglycemia }\end{array}$ & \multicolumn{2}{l}{ Diabetics } \\
\cline { 3 - 4 } & Yes & No \\
\hline Ciprofloxacin & $50.0 \%$ & $28.8 \%$ & $71.2 \%$ \\
Levofloxacin & $42.4 \%$ & $24.0 \%$ & $76.0 \%$ \\
Moxifloxacin & $7.6 \%$ & $33.3 \%$ & $66.7 \%$ \\
\hline
\end{tabular}

\section{Number of episodes}

Hyperglycemia was more common than hypoglycemia in all groups. The highest incidence of hyperglycemia occurred with levofloxacin in $70.0 \%$ of the cases, followed by $39.0 \%$ with ciprofloxacin, and $33.3 \%$ with moxifloxacin. In contrast, hypoglycemia did not occur in the ciprofloxacin group, but it was more common with moxifloxacin $(11.1 \%)$, followed by levofloxacin $(6.0 \%)$ (Table 11$)$.

\section{Concomitant medications}

A total of 47 patients were taking additional medications that can affect blood glucose levels concomitantly with their fluoroquinolone therapy. These medications included steroids, insulin regimens, and/or oral anti-diabetic agents.

\section{Discussion}

In Lebanon, concerns about microorganisms resistant to fluoroquinolones have emerged in both community and hospital settings. ${ }^{4}$ No large-scale studies have examined the inappropriate use of these agents and their impact on the Lebanese population. In our prospective observational study, we found that commonly prescribed fluoroquinolones were used according to the appropriate indication in $93.2 \%$ of the patients. This finding shows that fluoroquinolones are being prescribed appropriately in a hospital setting. However, dosing of these agents was adequate in only $74.6 \%$ of the patients and $57.2 \%$ did not receive the correct dose adjustment based on their level of renal impairment. In addition, only $57.6 \%$ of the patients received the appropriate duration of treatment. Based on the results of this study, the major clinical interventions for the future will involve adjusting the dose and duration of fluoroquinolones. Clinical pharmacists can have a great impact on decreasing the widespread resistance by reviewing and promoting rational antibiotic therapy. Thus, pharmacists in collaboration with other health care professionals can contribute to provide optimal patient care and appropriate drug use.

A major issue before the initiation of antimicrobial agents is to take cultures in all patients whenever possible. In our study, cultures were only taken from $59.3 \%$ of the patients. Clinical pharmacists can play a tremendous role in de-escalating treatment when indicated and in sparing the use of broad-spectrum fluoroquinolones.

Dysglycemic events were not restricted to diabetic patients. The glycemic control issue with fluoroquinolones became a concern in 2006 when Bristol-Myers Squibb stopped manufacturing Tequin ${ }^{\circledR}$ (gatifloxacin). ${ }^{12}$ Although most of the effects on glucose homeostasis have been linked to gatifloxacin, it should be noted that all fluoroquinolones can cause blood glucose fluctuations. ${ }^{20,32,33}$ Baseline blood glucose levels before the initiation of fluoroquinolones were checked only in $21.2 \%$ of the patients and $27.7 \%$ did not have their blood glucose monitored during therapy.

There is a growing body of literature documenting the increased complication rates of high blood glucose levels. ${ }^{32,33}$ Additionally, the literature documents the positive effect of tightly controlled glucose in various disease states, especially infections. ${ }^{32,33}$ Therefore, based on the institution sliding scale of insulin, we defined hyperglycemia when glucose levels exceeded $150 \mathrm{mg} / \mathrm{dL}$. Compared to other studies, this level is relatively stricter. Interestingly, hyperglycemia occurred frequently with levofloxacin $(70.0 \%)$, followed by ciprofloxacin $(39.0 \%)$ and moxifloxacin $(33.3 \%)$. Several confounding factors may have contributed to these findings. For example, the presence of stress factors and other disease state interactions may have increased blood glucose levels. In addition, $32.2 \%$ of the patients were taking steroids concomitantly with their fluoroquinolone therapy. This was a confounding factor in our study because the administration of a steroid can cause hyperglycemia due to a decrease in both insulin secretion and insulin sensitivity. Another confounding factor that could have affected the results was

Table I0 Blood glucose level monitoring

\begin{tabular}{|c|c|c|c|c|c|c|}
\hline \multirow[t]{3}{*}{ Fluoroquinolone } & \multicolumn{2}{|c|}{ Glucose monitoring } & \multicolumn{4}{|l|}{ Baseline } \\
\hline & \multirow[t]{2}{*}{ Yes } & \multirow[t]{2}{*}{ No } & \multicolumn{3}{|l|}{ Yes } & \multirow[t]{2}{*}{ No } \\
\hline & & & Normal & Hyperglycemia & Hypoglycemia & \\
\hline Ciprofloxacin & $49.2 \%$ & $50.8 \%$ & $13.6 \%$ & $22.0 \%$ & $1.7 \%$ & $62.7 \%$ \\
\hline Levofloxacin & $90.0 \%$ & $10.0 \%$ & $16.0 \%$ & $14.0 \%$ & $0.0 \%$ & $70.0 \%$ \\
\hline Moxifloxacin & $77.8 \%$ & $22.2 \%$ & $22.2 \%$ & $11.1 \%$ & $0.0 \%$ & $66.7 \%$ \\
\hline
\end{tabular}


Table I I Dysglycemia with fluoroquinolone therapy

\begin{tabular}{llll}
\hline Fluoroquinolone & \multicolumn{2}{l}{ Dysglycemia } & \\
\cline { 2 - 3 } & \multicolumn{2}{l}{ Yes } & No \\
\cline { 2 - 3 } & Hyperglycemia & Hypoglycemia & \\
\hline Ciprofloxacin & $39.0 \%$ & $0.0 \%$ & $61.0 \%$ \\
Levofloxacin & $70.0 \%$ & $6.0 \%$ & $24.0 \%$ \\
Moxifloxacin & $33.3 \%$ & $11.1 \%$ & $55.6 \%$ \\
\hline
\end{tabular}

that the baseline blood glucose levels were checked in only $21.2 \%$ of the patients; thus, a correlation between baseline and subsequently measured glucose concentrations was difficult to interpret.

On the other hand, the incidence of hypoglycemia was less common than hyperglycemia. Hypoglycemia was defined as blood glucose levels $<70 \mathrm{mg} / \mathrm{dL}$. In this study, $11.1 \%$ and $6.0 \%$ of the patients had hypoglycemic episodes in the moxifloxacin and levofloxacin groups, respectively, and none in the ciprofloxacin group. In this study, concomitant hypoglycemic drug treatment was the major interacting factor. For example, $11.0 \%$ and $5.1 \%$ of patients were taking insulin and oral antidiabetic drugs, respectively. In a case control study of 7,287 patients who received gatifloxacin or levofloxacin, $1.6 \%$ recorded a glucose level $<51 \mathrm{mg} / \mathrm{dL} .{ }^{34}$ This life-threatening side effect, which is often masked by the underlying disease, must be carefully monitored especially when fluoroquinolones are used.

Although our study was prospective in nature, it has several limitations. It was designed to be observational, which limits the pharmacist's interventions. In addition, the survival rate was not followed up and the pharmacists were not in direct contact with the patients.

\section{Conclusion}

Overall, our findings provided important implications for clinical practice. Major clinical interventions for the future will include adjusting the dose and duration of therapy with fluoroquinolones. The incidence of hypoglycemia with commonly prescribed fluoroquinolones was less than hyperglycemia. Underestimating the potential risk of dysglycemia associated with fluoroquinolone use may lead to serious complications in diabetic and nondiabetic patients.

\section{Disclosure}

No funding was received for this work. The authors report no conflicts of interest in this work.

\section{References}

1. Linder JA, Huang ES, Steinman MA, Gonzales R, Stafford RS. Fluoroquinolone prescribing in the United States: 1995 to 2002. Am JMed. 2005; 118(3):259-268.

2. King DE, Malone R, Lilley SH. New classification and update on the quinolone antibiotics. Am Fam Physician. 2000;61(9):2741-2748.

3. Oliphant CM, Green GM. Quinolones: a comprehensive review. Am Fam Physician. 2002;65(3):455-464.

4. Daoud Z, Hakime N. [Prevalence and susceptibility patterns of extendedspectrum betalactamase-producing Escherichia coli and Klebsiella pneumoniae in a general university hospital in Beirut, Lebanon]. Rev Esp Quimioter. 2003;16(2):233-238. Spanish.

5. Araj GF, Zaatari GS. Antimicrobial susceptibility patterns of bacterial isolates at the American University of Beirut Medical Center. June 1, 2012-June 30, 2013.

6. Shafran SD. Glucose homeostasis abnormalities and fluoroquinolones: a Canadian thought-leader perspective from Stephen D. Shafran MD, FRCPC. Medscape. 2005;11(1): .

7. Frothingham R. Glucose homeostasis abnormalities associated with use of gatifloxacin. Clin Infect Dis. 2005;41(9):1269-1276.

8. Food and Drug Administration. Temafloxacin P92-16. 1998.

9. Rubenstein E. History of quinolones and their side effects. Chemotherapy. 2001;47 Suppl 3:3-8; discussion 44-48.

10. Ball P. New antibiotics for community-acquired lower respiratory tract infections: improved activity at a cost? Int J Antimicrob Agents. 2000; 16(3):263-272.

11. Center for Drug Evaluation and Review, Office of Drug Safety. Questions and Answers on Trovafloxacin: Public Health Advisory. Silver Spring, MD: Food and Drug Administration; 2003.

12. Schmid RE [webpage on the Internet]. Drug company taking Tequin off market. Associated Press; 2006. Available from: http://www. highbeam.com/doc/1P1-122828738.html. Accessed: November 10, 2014.

13. Biggs WS. Hypoglycemia and hyperglycemia associated with gatifloxacin use in elderly patients. $J$ Am Board Fam Pract. 2003;16(5): 455-457.

14. Yamada C, Nagashima K, Takahashi A, et al. Gatifloxacin acutely stimulates insulin secretion and chronically suppresses insulin biosynthesis. Eur J Pharmacol. 2006;553(1-3):67-72.

15. Maeda N, Tamagawa T, Niki I, et al. Increase in insulin release from rat pancreatic islets by quinolone antibiotics. $\mathrm{Br} J$ Pharmacol. 1996;117(2):372-376.

16. Ghaly H, Kriete C, Sahin S, et al. The insulinotropic effect of fluoroquinolones. Biochem Pharmacol. 2009;77(6):1040-1052.

17. Saraya A, Yokokura M, Gonoi T, Seino S. Effects of fluoroquinolones on insulin secretion and beta-cell ATP-sensitive $\mathrm{K}+$ channels. Eur $J$ Pharmacol. 2004;497(1):111-117.

18. Ishiwata $\mathrm{Y}$, Itoga $\mathrm{Y}$, Yasuhara M. Effect of levofloxacin on serum glucose concentration in rats. Eur J Pharmacol. 2006;551(1-3): 168-174.

19. Menzies DJ, Dorsainvil PA, Cunha BA, Johnson DH. Severe and persistent hypoglycemia due to gatifloxacin interaction with oral hypoglycemic agents. Am J Med. 2002;113(3):232-234.

20. Mohr JF, McKinnon PS, Peymann PJ, Kenton I, Septimus E, Okhuysen PC. A retrospective, comparative evaluation of dysglycemias in hospitalized patients receiving gatifloxacin, levofloxacin, ciprofloxacin, or ceftriaxone. Pharmacotherapy. 2005;25(10):1303-1309.

21. Ge DT, Law PY, Kong SK, Ho YY. Disturbance of cellular glucose transport by two prevalently used fluoroquinolone antibiotics ciprofloxacin and levofloxacin involves glucose transporter type 1. Toxicol Lett. 2009;184(2):81-84.

22. Lawrence KR, Adra M, Keir C. Hypoglycemia-induced anoxic brain injury possibly associated with levofloxacin. $J$ Infect. 2006;52(6): e177-e180. 
23. Gupta K, Hooton TM, Naber KG, et al. International clinical practice guidelines for the treatment of acute uncomplicated cystitis and pyelonephritis in women: a 2010 update by the Infectious Diseases Society of America and the European Society for Microbiology and Infectious Diseases. Clin Infect Dis. 2011;52(5):e103-e120.

24. Stevens DL, Bisno AL, Chambers HF, et al. Practice guidelines for the diagnosis and management of skin and soft tissue infections: 2014 update by the Infectious Diseases Society of America. Clin Infect Dis 2014, 59(2):e10-e52.

25. Lipsky BA, Berendt AR, Cornia PB, et al. Infectious Diseases Society of America executive summary 2012: Infectious Diseases Society of America practice guideline for the diagnosis and treatment of diabetic foot infections. Clin Infect Dis. 2012;54:1679-1684.

26. Solomkin JS, Mazuski JE, Bradley JS, et al. Diagnosis and managemen of complicated intra-abdominal infection in adults and children: guideli nes by the Surgical Infection Society and the Infectious Diseases Society of America. Clin Infect Dis. 2010;50:133-64.

27. Lionel A. Mandell, Richard G. Wunderink, et al. Infectious Diseases Society of America/American Thoracic Society Consensus Guidelines on the Management of Community-Acquired Pneumonia in Adults Clin Infect Dis. 2007;44(Suppl 2):S27-S72. doi:10.1086/511159.
28. Guidelines for the management of adults with hospital-acquired, ventilator-associated, and healthcare-associated pneumonia. Am J Respir Crit Care Med. 2005;171(4):388-416.

29. Ciprofloxacin [package insert]. Wayne, NJ: Bayer Healthcare; 2009.

30. Levofloxacin [package insert]. Inc Raritan, NJ: Ortho-McNeil-Janssen; 2008.

31. Moxifloxacin [package insert]. Whitehouse Station, NJ Bayer Healthcare; 2013.

32. Vue MH, Setter SM. Drug-Induced Glucose Alterations Part 1: DrugInduced Hypoglycemia. Diabetes Spectrum. 2011;24(3):171-177.

33. Rehman A, Setter SM, Vue MH. Drug-Induced Glucose Alterations Part 2: Drug-Induced Hyperglycemia. Diabetes Spectrum. 2011;24(4):234-238.

34. Graumlich JF, Habis S, Avelino RR, et al. Hypoglycemia in inpatients after gatifloxacin or levofloxacin therapy: nested case-control study. Pharmacotherapy. 2005;25(10):1296-1302. 


\section{Supplementary materials}

Table SI Ciprofloxacin oral dosage

\begin{tabular}{|c|c|c|c|c|}
\hline $\begin{array}{l}\text { Ciprofloxacin } \\
\text { (FDA-approved indication) }\end{array}$ & Severity & $\begin{array}{l}\text { PO dose } \\
\text { (adult) }\end{array}$ & Frequency & Duration \\
\hline \multirow[t]{3}{*}{ UTI } & Acute uncomplicated & $250 \mathrm{mg}$ & $\mathrm{q} 12 \mathrm{~h}$ & 3 days \\
\hline & Mild/moderate & $250 \mathrm{mg}$ & $\mathrm{q} 12 \mathrm{~h}$ & $7-14$ days \\
\hline & Severe/complicated & $500 \mathrm{mg}$ & $\mathrm{q} / 2 \mathrm{~h}$ & $7-14$ days \\
\hline Chronic prostatitis & Mild/moderate & $500 \mathrm{mg}$ & $\mathrm{q} 12 \mathrm{~h}$ & 28 days \\
\hline Acute sinusitis & Mild/moderate & $500 \mathrm{mg}$ & $\mathrm{q} 12 \mathrm{~h}$ & 10 days \\
\hline \multirow[t]{2}{*}{ Lower RTI } & Mild/moderate & $500 \mathrm{mg}$ & $\mathrm{q} 12 \mathrm{~h}$ & $7-14$ days \\
\hline & Severe/complicated & $750 \mathrm{mg}$ & $\mathrm{q} 12 \mathrm{~h}$ & $7-14$ days \\
\hline \multirow[t]{2}{*}{ SSTI } & Mild/moderate & $500 \mathrm{mg}$ & $\mathrm{q} 12 \mathrm{~h}$ & $7-14$ days \\
\hline & Severe/complicated & $750 \mathrm{mg}$ & $\mathrm{q} 12 \mathrm{~h}$ & $7-14$ days \\
\hline \multirow[t]{2}{*}{ Bone and joints } & Mild/moderate & $500 \mathrm{mg}$ & $\mathrm{q} 12 \mathrm{~h}$ & 4-6 weeks \\
\hline & Severe/complicated & $750 \mathrm{mg}$ & $\mathrm{q} 12 \mathrm{~h}$ & 4-6 weeks \\
\hline Infectious diarrhea & Mild/moderate/severe & $500 \mathrm{mg}$ & $\mathrm{q} 12 \mathrm{~h}$ & $5-7$ days \\
\hline Typhoid fever & Mild/moderate & $500 \mathrm{mg}$ & $\mathrm{q} 12 \mathrm{~h}$ & 10 days \\
\hline Intra-abdominal & Complicated & $500 \mathrm{mg}$ & $\mathrm{q} / 2 \mathrm{~h}$ & $7-14$ days \\
\hline Neisseria gonorrhoeae & Uncomplicated & $250 \mathrm{mg}$ & Single dose & Single dose \\
\hline
\end{tabular}

Notes: Ciprofloxacin should be used as $400 \mathrm{mg}$ IV q $8 \mathrm{~h}$ or $750 \mathrm{mg}$ PO q $12 \mathrm{~h}$ for febrile neutropenia and nosocomial pneumonia for patients with normal kidney function. Abbreviations: FDA, United States Food and Drug Administration; PO, per os; UTI, urinary tract infection; q 12 h, every 12 hours; RTI, respiratory tract infection; SSTI, skin and soft tissue infection; IV, intravenous; q 8 h, every 8 hours.

Table S2 Ciprofloxacin equivalent AUC dosing regimen

\begin{tabular}{ll}
\hline $\begin{array}{l}\text { Ciprofloxacin } \\
\text { oral dosage }\end{array}$ & $\begin{array}{l}\text { Equivalent ciprofloxacin IV } \\
\text { dosage }\end{array}$ \\
\hline $250 \mathrm{mg}$ tablet q I2 h & $200 \mathrm{mg} \mathrm{IV} \mathrm{q} \mathrm{I2} \mathrm{h}$ \\
$500 \mathrm{mg}$ tablet q I2 h & $400 \mathrm{mg} \mathrm{IV} \mathrm{q} \mathrm{I2} \mathrm{h}$ \\
$750 \mathrm{mg}$ tablet q I2 h & $400 \mathrm{mg} \mathrm{IV} \mathrm{q} 8 \mathrm{~h}$ \\
\hline
\end{tabular}

Abbreviations: AUC, area under the curve; IV, intravenous; $\mathrm{q} / 2 \mathrm{~h}$, every 12 hours; $98 \mathrm{~h}$, every 8 hours.

Table S4 Levofloxacin oral/IV dosage

\begin{tabular}{|c|c|c|c|}
\hline $\begin{array}{l}\text { Levofloxacin (FDA- } \\
\text { approved indication) }\end{array}$ & $\begin{array}{l}\text { PO/IV dose } \\
\text { (adult) }\end{array}$ & Frequency & Duration \\
\hline \multirow[t]{2}{*}{ AECB } & $500 \mathrm{mg}$ & $\mathrm{q} 24 \mathrm{~h}$ & 7 days \\
\hline & $750 \mathrm{mg}$ & q $24 \mathrm{~h}$ & 5 days \\
\hline \multirow[t]{2}{*}{ CAP } & $500 \mathrm{mg}$ & q $24 \mathrm{~h}$ & $7-14$ days \\
\hline & $750 \mathrm{mg}$ & $\mathrm{q} 24 \mathrm{~h}$ & 5 days \\
\hline \multirow[t]{2}{*}{ Sinusitis } & $500 \mathrm{mg}$ & q $24 \mathrm{~h}$ & $10-14$ days \\
\hline & $750 \mathrm{mg}$ & q $24 \mathrm{~h}$ & 5 days \\
\hline HAP & $750 \mathrm{mg}$ & $\mathrm{q} 24 \mathrm{~h}$ & $7-14$ days \\
\hline Uncomplicated SSTI & $500 \mathrm{mg}$ & $\mathrm{q} 24 \mathrm{~h}$ & $7-10$ days \\
\hline Complicated SSTI & $750 \mathrm{mg}$ & $\mathrm{q} 24 \mathrm{~h}$ & $7-14$ days \\
\hline Chronic prostatitis & $500 \mathrm{mg}$ & q $24 \mathrm{~h}$ & 28 days \\
\hline \multirow[t]{2}{*}{ Complicated UTI } & $250 \mathrm{mg}$ & q $24 \mathrm{~h}$ & 10 days \\
\hline & $750 \mathrm{mg}$ & q $24 \mathrm{~h}$ & 5 days \\
\hline \multirow[t]{2}{*}{ Acute pyelonephritis } & $250 \mathrm{mg}$ & q $24 \mathrm{~h}$ & 10 days \\
\hline & $750 \mathrm{mg}$ & q $24 \mathrm{~h}$ & 5 days \\
\hline Uncomplicated UTI & $250 \mathrm{mg}$ & $\mathrm{q} 24 \mathrm{~h}$ & 3 days \\
\hline
\end{tabular}

Abbreviations: FDA, United States Food and Drug Administration; PO, per os; IV, intravenous; $A E C B$, acute exacerbations of chronic bronchitis; q 24 h, every 24 hours; CAP, community-acquired pneumonia; HAP, hospital-acquired pneumonia; SSTI, skin and soft tissue infection; UTI, urinary tract infection.
Table S3 Adjustment of ciprofloxacin dose in renal impairment

\begin{tabular}{ll}
\hline $\mathrm{CrCl} 25-49 \mathrm{~mL} /$ minute & $200-400 \mathrm{mg} \mathrm{IV} \mathrm{q} 12 \mathrm{~h}$ \\
& $250-500 \mathrm{mg}$ PO q I2 h \\
$\mathrm{CrCl}<25 \mathrm{~mL} /$ minute & $200 \mathrm{mg}$ IV q I2 h \\
& $250-500 \mathrm{mg}$ PO q $24 \mathrm{~h}$ \\
Hemodialysis & $250-500 \mathrm{mg}$ PO q $24 \mathrm{~h}$ (after dialysis)
\end{tabular}

Abbreviations: $\mathrm{CrCl}$, creatinine clearance; IV, intravenous; $\mathrm{q} 12 \mathrm{~h}$, every 12 hours; PO, per os; q 24 h, every 24 hours.

Table S5 Adjustment of levofloxacin dose in renal impairment Acute sinusitis, AECB, CAP, uncomplicated SSTI, chronic bacterial prostatitis

$\mathrm{CrCl}>50 \mathrm{~mL} /$ minute No dosage adjustment required

$\mathrm{CrCl} 20-49 \mathrm{~mL} /$ minute $\quad 500 \mathrm{mg}$ then $250 \mathrm{mg} \mathrm{q} 24 \mathrm{~h}$

$\mathrm{CrCl} \mathrm{10-19} \mathrm{mL/minute} \quad 500 \mathrm{mg}$ then $250 \mathrm{mg} \mathrm{q} 48 \mathrm{~h}$

Hemodialysis $500 \mathrm{mg}$ then $250 \mathrm{mg}$ q $48 \mathrm{~h}$

Complicated SSTI, nosocomial pneumonia

$\mathrm{CrCl} 20-49 \mathrm{~mL} /$ minute $\quad 750 \mathrm{mg}$ q $48 \mathrm{~h}$

$\mathrm{CrCl} \mathrm{10-19} \mathrm{mL/minute} \quad 500 \mathrm{mg} \mathrm{q} 48 \mathrm{~h}$

Abbreviations: $A E C B$, acute exacerbations of chronic bronchitis; $C A P$, communityacquired pneumonia; SSTI, skin and soft tissue infection; $\mathrm{CrCl}$, creatinine clearance; q 24 h, every 24 hours; q 48 h, every 48 hours. 
Table S6 Moxifloxacin oral/IV dosage

\begin{tabular}{lllc}
\hline $\begin{array}{l}\text { Moxifloxacin } \\
\text { (FDA-approved indication) }\end{array}$ & $\begin{array}{l}\text { PO/IV dose } \\
\text { (adult) }\end{array}$ & Frequency & Duration \\
\hline Acute bacterial sinusitis & $400 \mathrm{mg}$ & $\mathrm{q} 24 \mathrm{~h}$ & 10 days \\
AECB & $400 \mathrm{mg}$ & $\mathrm{q} 24 \mathrm{~h}$ & 5 days \\
CAP & $400 \mathrm{mg}$ & $\mathrm{q} 24 \mathrm{~h}$ & 10 days \\
Uncomplicated SSTI & $400 \mathrm{mg}$ & $\mathrm{q} 24 \mathrm{~h}$ & 7 days \\
Complicated SSTI & $400 \mathrm{mg}$ & $\mathrm{q} 24 \mathrm{~h}$ & $7-21$ days \\
Complicated intra-abdominal infections & $400 \mathrm{mg}$ & $\mathrm{q} 24 \mathrm{~h}$ & $5-14$ days \\
\hline
\end{tabular}

Abbreviations: FDA, United States Food and Drug Administration; AECB, acute exacerbations of chronic bronchitis; CAP, community-acquired pneumonia; SSTI, skin and soft tissue infection; q 24 h, every 24 hours.

\section{Publish your work in this journal}

Therapeutics and Clinical Risk Management is an international, peerreviewed journal of clinical therapeutics and risk management, focusing on concise rapid reporting of clinical studies in all therapeutic areas, outcomes, safety, and programs for the effective, safe, and sustained use of medicines. This journal is indexed on PubMed Central, CAS,
EMBase, Scopus and the Elsevier Bibliographic databases. The manuscript management system is completely online and includes a very quick and fair peer-review system, which is all easy to use. Visit http://www.dovepress.com/testimonials.php to read real quotes from published authors.

Submit your manuscript here: http://www.dovepress.com/therapeutics-and-clinical-risk-management-journal 